Article

\title{
Quantifying the Effects of Wood Moisture and Temperature Variation on Time-of-Flight Acoustic Velocity Measures within Standing Red Pine and Jack Pine Trees
}

\author{
Peter F. Newton \\ Canadian Wood Fibre Centre, Canadian Forest Service, Natural Resources Canada, Sault Ste. Marie, \\ ON P6A 2E5, Canada; peter.newton@canada.ca; Tel.: +1-705-541-5615
}

Received: 2 August 2018; Accepted: 27 August 2018; Published: 30 August 2018

\begin{abstract}
The relationship between the dynamic modulus of elasticity $\left(m_{e}\right)$ of xylem tissue and acoustic velocity $\left(v_{d}\right)$ has been established for a number of commercially-important coniferous species, including red pine (Pinus resinosa Ait.) and jack pine (Pinus banksiana Lamb.). However, $v_{d}$ has been shown to vary systematically with xylem temperature $\left(t_{x}\right)$ and moisture $\left(m_{x}\right)$ for some species, and hence when the calibrated $m_{e_{-}} v_{d}$ relationships are used outside of the range of conditions under which they were parameterized, erroneous predictions may arise. Consequently, the objectives of this study were (1) to investigate the significance of $t_{x}$ and $m_{x}$ effects on $v_{d}$ measurements within standing red pine and jack pine trees, and (2), given (1), to develop correction equations for standardizing $v_{d}$ measurements to referenced $t_{x}$ and $m_{x}$ conditions if warranted. Analytically, based on a temporal replicated sampling design, 26 mature red pine and 36 semi-mature jack pine trees growing in managed plantations located within central Ontario, Canada (Kirkwood Forest, Great Lakes-St. Lawrence Forest Region), were continuously measured for $v_{d}, t_{x}$, and $m_{x}$ during the spring-to-autumn seasonal periods in 2016 (red pine) and 2017 (jack pine). A total of 6 measurement events per species occurred at approximately 4-8 week intervals in which a total of 624 red pine and 864 jack pine cardinal-specific (north, east, south, and west) breast-height acoustic velocity, xylem temperature, and xylem moisture measurements were obtained: Yielding a total of 156 red pine and 216 jack pine mean tree-based values available for analysis. Over the sampling periods, (1) mean tree xylem temperatures ranged from a minimum of $3^{\circ} \mathrm{C}$ to a maximum of $31^{\circ} \mathrm{C}$ (mean $=19.2{ }^{\circ} \mathrm{C}$ ) in red pine and from a minimum of $0{ }^{\circ} \mathrm{C}$ to a maximum of $27^{\circ} \mathrm{C}\left(\mathrm{mean}=16.5^{\circ} \mathrm{C}\right)$ in jack pine, and (2) mean tree xylem moistures ranged from a minimum 31\% to a maximum of $45 \%$ ( mean $=38.6 \%$ ) in red pine and from a minimum $25 \%$ to a maximum of $50 \%$ (mean $=38.8 \%$ ) in jack pine. Graphical examination of the moisture effect on the $v_{d}$ and $t_{x}$ relationship by tree and species revealed inversely proportional, linear-like trends at lower moisture levels and directly-proportional, linear-like trends at higher moisture levels where the effect was more evident for red pine than for jack pine. In order to describe this multivariate relationship, species-specific, two-level hierarchical, mixed-effects linear models inclusive of random and fixed effects were specified and subsequently parameterized. The first-level model described the tree-specific $v_{d}-t_{x}$ relationship deploying a simple linear regression specification, whereas the second-level model expressed the first-level parameter estimates as a linear function of seasonal mean tree moisture. The resultant statistically-validated, parameterized regression models, for which $64 \%$ (red pine) and $90 \%$ (jack pine) of the $v_{d}$ variation was explained, indicated that the $v_{d}-t_{x}$ relationship varied systematically with seasonal mean moisture level in red pine but not so in jack pine. More precisely, in red pine, $v_{d}$ declined with increasing $t_{x}$ at lower moisture levels $(<38 \%)$, but increased with increasing $t_{x}$ at higher moisture levels $(>38 \%)$. Conversely, although $v_{d}$ declined with increasing $t_{x}$ in jack pine, the relationship was unaffected by changes in seasonal mean tree moisture levels. Consequently, based on the final hierarchical model specifications, correction equations for adjusting observed $v_{d}$ values to standardized temperature
\end{abstract}


$\left(20^{\circ} \mathrm{C}\right)$ and moisture conditions ( $40 \%$ for red pine) were developed for each species. Across the range of temperatures $\left(\approx 5{ }^{\circ} \mathrm{C}-30^{\circ} \mathrm{C}\right)$ and mean moisture levels $(\approx 30-45 \%)$ examined, these equations generated a mean absolute $v_{d}$ adjustment of approximately $0.12 \mathrm{~km} / \mathrm{s}$ for red pine and $0.04 \mathrm{~km} / \mathrm{s}$ for jack pine. However, based on the corresponding relative magnitude of these adjustments which account for the narrow species-specific $v_{d}$ sample ranges observed $(0.80$ and $0.85 \mathrm{~km} / \mathrm{s}$ for red pine and jack pine, respectively), the standardization of $v_{d}$ estimates could be of operational significance when acoustic sampling during periods in which xylem temperature and moisture levels approach the extremities of their spring-to-autumn seasonal ranges. Overall, the results of this empirical-based assessment, which confirmed the presence of temperature and moisture induced variation in acoustic velocity measures within standing red pine and jack pine trees, were largely in accordance with expectation. The subsequent provision of species-specific correction functions for adjusting observed $v_{d}$ sample values to corresponding equivalents referenced to standardized temperature and moisture conditions could assist in mitigating the consequences of environmental variability when acoustic sampling.

Keywords: hierarchical linear mixed-effects regression models; species-specific correction equations; precision requirements

\section{Introduction}

Red pine (Pinus resinosa Ait.) and jack pine (Pinus banksiana Lamb.) are intensely-managed and commercially-important species that occupy a wide range of sandy textured sites throughout the Great Lakes-St. Lawrence and Boreal Forest Regions of North America [1]. These species produce a broad array of economically important end-products such as appearance-based boards for interior flooring, exterior decking and wall paneling, dimensional lumber for residential home construction, utility poles for building electrical transmission grids, veneer for furniture manufacturing, pulp and paper products, and engineered wood composites [2]. In order to optimize end-product recovery given this range of end-products, in-forest, non-destructive forecasting tools could be of consequential utility in terms of pre-harvest identification of end-product potential and informing post-harvest segregation decision-making so that the extracted raw fiber is routed to the most appropriate conversion facility (e.g., pulp and paper mills, stud and randomized length sawmills, or pole processing yards). Among the array of non-destructive methodologies used to estimate commercially-relevant wood attributes (see [3] for a comprehensive overview), acoustic-based methods have gained considerable currency in forest segregation operations given their ability to readily estimate one of the principal fiber attributes underlying solid-wood end-product type and grade: The modulus of elasticity (sensu [4]). Commercially available time-of-flight acoustic velocity instruments, such as the Director ST300 developed by Fibre-gen Inc. of Christchurch, New Zealand (e.g., [5]), and the TreeSonic microsecond timer developed by Fakopp Enterprise, Ágfalva, Hungary (e.g., [6]), can efficiently provide dynamic-based wood stiffness estimates for standing trees without restoring to more expensive and logistically challenging destructive methods (e.g., core extraction followed by Silviscan analysis).

More specifically, the relationship between the dynamic modulus of elasticity (MOE denoted $m_{e}$ in this study) of the xylem tissue within standing trees and acoustic velocity ( $v_{d}$; dilatational stress wave) has been established for numerous coniferous species including red pine [7] and jack pine [8]. Although there are many possible uses of the $m_{e}-v_{d}$ relationship in both forest management and research, it has principally been deployed in pre-harvest surveys of end-product potential, segregation decision-making, and silvicultural experimentation when destructive methods are prohibited. However, acoustic velocity is known to vary by a multitude of internal factors related to the heterogeneity of the wood structure (e.g., ring width (growth rate) variation, knot distribution), in addition to the physical properties of the wood, when measured. With respect to these latter 
sources of variation, xylem temperature and wood moisture levels have been identified as being among the most important (e.g., [9-12]). Consequently, when acoustic-attribute relationships are used outside of the range of temperature and moisture conditions under which they were parameterized, erroneous predictions and associated end-product forecasts may occur.

Although limited to a small number of species, standardization equations which attempt to account for temperature and moisture effects on acoustic velocity measurements, have been developed (e.g., Scot pine (Pinus sylvestris L.); radiata pine (Pinus radiata D. Don), Salzmann pine (Pinus nigra salzmanni (Dunal) Franco), and maritime pine (Pinus pinaster Ait.); [13]). These equations adjust observed $v_{d}$ sample values to corresponding equivalents referenced to standardized temperature and moisture conditions. However, the majority of the correction equations developed to date have been parameterized using measurement values obtained from solid wood end-products (e.g., sawn boards [12,14]) rather than from standing trees. Nevertheless, these research efforts have contributed to a more in-depth understanding of the importance of this issue when acoustic sampling, in addition to providing computational solutions for specific species.

Operationally, the acoustic approach to predicting internal fiber attributes within standing trees is increasingly being employed in (1) operational pre-harvest, end-product surveys in order to increase segregation efficiency and profit margins (e.g., $[15,16])$, and (2) silvicultural experimentation where acoustic velocity is utilized as a surrogate response metric for inferring wood quality (e.g., fertilization [17] and tree improvement [18] studies). Consequently, failure to account for the effect of temperature and moisture variation on acoustic velocity estimates could potentially lead to erroneous end-product forecasts in forest operations or statistical inference when analyzing experimental and survey results. Thus, with respect to standing red pine and jack pine trees for which a suite of acoustic-based fiber prediction models have been developed ([7,8], respectively), the objectives of this study were (1) to investigate the significance of xylem temperature and moisture effects on acoustic velocity, and (2), given (1), to develop correction equations for adjusting acoustic velocity measurements to standardized conditions if required.

\section{Materials and Methods}

\subsection{Data Acquisition: Study Sites, Tree Selection and Associated Measurements}

Twenty-six 85 year-old red pine and thirty-six 48 year-old jack pine trees growing in plantations established on good quality sites (site indices of $22 \mathrm{~m}$ at 50 years for both species, as determined from site-specific, height-age functions (i.e., [19] for red pine and [20] for jack pine)) in the Kirkwood Forest, which falls within Forest Section L.10-Algoma of the Great Lakes-St. Lawrence Forest Region [1], were chosen for repeated temporal-based measurement of acoustic velocity $\left(v_{d} ; \mathrm{km} / \mathrm{s}\right)$, xylem temperature $\left(t_{x} ;{ }^{\circ} \mathrm{C}\right)$, and xylem moisture $\left(m_{x} ; \%\right)$. Procedurally, for each of the replicated sampling events during the 2016 ( $n=6$ for red pine) and 2017 ( $n=6$ for jack pine) spring-to-autumn seasonal period, the following measurements were taken on each sample tree: (1) Twice-replicated mean $v_{d}$ measurements, which were generated from 8 consecutive individual $v_{d}$ estimates obtained on each cardinal-specific (north, east, south, and west) circumferential face using the ST300 time-of-flight acoustic velocity tool ( $\pm 0.01 \mathrm{~km} / \mathrm{s}$; Fibre-gen Inc., New Zealand); the transmitter (impact) and receiving probes were positioned at stem heights of approximately $0.5 \mathrm{~m}$ and $1.5 \mathrm{~m}$, respectively; and (2) cardinal-specific, breast-height $(1.3 \mathrm{~m})$ xylem temperature $t_{x}\left( \pm 0.1^{\circ} \mathrm{C}\right)$ and temperature-adjusted $m_{x}$ $( \pm 0.1 \%)$ measurements at an xylem depth of approximately $3 \mathrm{~cm}$ from the periderm circumferential surface as determined using a Gann Hydromette M 4050 electrical-resistance, multi-functional meter equipped with a Gann M 18 Electrode (Gann Inc., Gerlingen, Germany). Note, preceding each sampling event, all measuring devices, including the ST300, were validated in terms of their expected measurement tolerances as per manufacture's specifications.

More specifically, the 26 red pine trees situated within 3 experimental treatment plots that belonged to the Beckwith thinning trial, were selected for continuous temporal monitoring in the 
spring of 2016. Specifically, based on tree lists derived from 360-degree prism sweeps (BAF $=2 \mathrm{~m}^{2}$ ) from the centre point of each experimental plot, a total of 26 sample trees were selected from the 3 plots: (1) 10 trees within Plot 6, which received 5 relatively heavy thinning treatments in order to maintain a comparatively low level of site occupancy (relative spacing index of $19 \%$ (mean intertree distance/dominant height ratio [21])); (2) 10 trees within Plot 8, which received 5 relatively moderate thinning treatments in order to maintain a comparatively moderate level of site occupancy (relative spacing index of 16\%); and (3) 6 trees within Plot 9, which received no thinning treatments in order to maintain a comparatively high level of site occupancy (relative spacing index of 13\%). Following initial tree measurements at the time of plot establishment, each sample tree was subsequently measured at approximately 4-8 week periodic intervals over the 2016 spring-to-autumn seasonal period. A total of 6 measurement data sets were obtained over six 2-day sampling events occurring specifically on the 28th and 29th of April, 31st of May and 1st of June, 28th and 29th of June, 3rd and 4th of August, 7th and 9th of September, and 3rd and 4th of October. Each sampling event yielded 104 cardinal-specific acoustic velocity, xylem temperature, and xylem moisture measurements (4 cardinal measurements per tree $\times 26$ trees/sampling event).

The 36 jack pine trees were chosen within 2 plantations that were established in 1969. The first plantation that was established at an initial density of 1134 stems/ha was left unthinned. Conversely, the second plantation was established at a higher initial density (1559 stems/ha) and was pre-commercially thinned at an age of 25 , during which approximately 581 stems/ha were removed, resulting in a residual crop density of approximately 978 stems/ha. In the spring of 2017, tree lists derived from 360-degree prism sweeps $\left(\mathrm{BAF}=2 \mathrm{~m}^{2}\right.$ ) at 3 systematically located points within each plantation, were used to randomly select 6 trees per plot for continuous monitoring. These sample trees were then subsequently measured at approximately 4-8 week periodic intervals over the 2017 spring-to-autumn seasonal period. A total of 6 measurement sets were obtained over six 2-day sampling events occurring on the 11th and 12th of May, 12th and 13th of June, 4th and 5th of July, 9th and 10th of August, 18th and 19th of September, and 7th and 8th of November. Each sampling event yielded 144 cardinal-specific acoustic velocity, xylem temperature, and xylem moisture measurements ( 4 cardinal measurements per tree $\times 36$ trees/sampling event).

Collectively, a total of 624 and 864 cardinal-specific acoustic velocity, xylem temperature, and xylem moisture measurements, distributed periodically at approximate equal time intervals throughout the spring-to-autumn seasonal periods, were obtained from the 26 red pine and 36 jack pine sample trees, respectively. Computationally, the cardinal-based measurements were combined in order to generate a mean acoustic velocity $\left(v_{d}\right)$, xylem temperature $\left(t_{x}\right)$, and xylem moisture $\left(m_{x}\right)$ value for each tree at each measurement. This resulted in a total of $156 v_{d}, t_{x}$, and $m_{x}$ observational data sets from the 26 red pine sample trees, and $216 v_{d}, t_{x}$, and $m_{x}$ observational data sets from the 36 jack pine sample trees, available for analysis. Over the sampling periods, (1) mean tree xylem temperatures ranged from a minimum of $3{ }^{\circ} \mathrm{C}$ to a maximum of $31^{\circ} \mathrm{C}\left(\right.$ mean $\left.=19.2{ }^{\circ} \mathrm{C}\right)$ in red pine and from a minimum of $0{ }^{\circ} \mathrm{C}$ to a maximum of $27^{\circ} \mathrm{C}$ (mean $=16.5^{\circ} \mathrm{C}$ ) in jack pine, and (2) mean tree xylem moistures were all above the fiber saturation level $(\approx 25 \%)$ and ranged from a minimum $31 \%$ to a maximum of $45 \%$ (mean $=38.6 \%$ ) in red pine and from a minimum $25 \%$ to a maximum of $50 \%$ (mean $=38.8 \%$ ) in jack pine. Table 1 provides a more comprehensive statistical summary of these data sets by species and sampling event. 
Table 1. Descriptive statistical summary of the mean tree-level acoustic velocity, xylem temperature, and xylem moisture measurements obtained from the 26 red pine and 36 jack pine sample trees by sampling event.

\begin{tabular}{|c|c|c|c|c|c|c|c|c|c|c|c|c|c|}
\hline \multirow{2}{*}{ Species } & \multirow{2}{*}{$\begin{array}{c}\text { Sampling Event } \\
\text { (Date: Day/Month/Year) }\end{array}$} & \multicolumn{4}{|c|}{ Acoustic Velocity $\left(v_{d} ; \mathrm{km} / \mathrm{s}\right)$} & \multicolumn{4}{|c|}{ Xylem Temperature $\left(t_{x} ;{ }^{\circ} \mathrm{C}\right)$} & \multicolumn{4}{|c|}{ Xylem Moisture $\left(m_{x} ; \%\right)$} \\
\hline & & $\bar{x}$ & Min & Max & $S E$ & $\bar{x}$ & Min & Max & $S E$ & $\bar{x}$ & Min & Max & $S E$ \\
\hline Red & $1(28,29 / 4 / 16)$ & 4.85 & 4.57 & 5.05 & 0.02 & 9.1 & 3.2 & 12.8 & 0.48 & 38.6 & 35.8 & 41.1 & 0.31 \\
\hline \multirow{5}{*}{ pine } & $2(31,1 / 5,6 / 16)$ & 4.90 & 4.72 & 5.11 & 0.02 & 18.6 & 15.4 & 22.6 & 0.45 & 37.8 & 32.4 & 42.5 & 0.42 \\
\hline & $3(28,29 / 6 / 16)$ & 4.84 & 4.49 & 5.09 & 0.03 & 20.4 & 18.0 & 23.8 & 0.36 & 35.9 & 30.7 & 39.4 & 0.38 \\
\hline & $4(3,4 / 8 / 16)$ & 4.85 & 4.62 & 5.22 & 0.03 & 27.5 & 24.1 & 30.9 & 0.34 & 38.2 & 32.0 & 42.1 & 0.50 \\
\hline & $5(7,9 / 9 / 16)$ & 4.85 & 4.66 & 5.22 & 0.03 & 22.8 & 16.5 & 25.2 & 0.46 & 40.9 & 31.3 & 45.2 & 0.66 \\
\hline & $6(3,4 / 10 / 16)$ & 4.88 & 4.67 & 5.29 & 0.03 & 16.9 & 13.5 & 19.6 & 0.37 & 40.1 & 34.7 & 42.7 & 0.35 \\
\hline Jack & $1(11,12 / 5 / 17)$ & 4.46 & 4.07 & 4.83 & 0.03 & 15.0 & 9.7 & 20.4 & 0.49 & 39.9 & 33.7 & 49.6 & 0.71 \\
\hline \multirow[t]{5}{*}{ pine } & $2(12,13 / 6 / 17)$ & 4.42 & 4.09 & 4.76 & 0.03 & 22.3 & 18.1 & 24.8 & 0.30 & 43.0 & 36.1 & 49.9 & 0.57 \\
\hline & $3(4,5 / 7 / 17)$ & 4.38 & 4.03 & 4.72 & 0.03 & 22.0 & 17.0 & 26.4 & 0.37 & 39.8 & 33.2 & 46.5 & 0.60 \\
\hline & $4(9,10 / 8 / 17)$ & 4.37 & 4.03 & 4.69 & 0.03 & 20.6 & 18.5 & 22.4 & 0.18 & 38.2 & 31.1 & 49.4 & 0.71 \\
\hline & $5(18,19 / 9 / 17)$ & 4.37 & 4.01 & 4.73 & 0.02 & 17.5 & 13.1 & 20.9 & 0.38 & 39.8 & 30.9 & 46.8 & 0.66 \\
\hline & $6(7,8 / 11 / 17)$ & 4.49 & 4.09 & 4.74 & 0.02 & 1.7 & 0.0 & 2.7 & 0.09 & 32.3 & 25.4 & 42.3 & 0.58 \\
\hline
\end{tabular}

$\bar{x}$, Min, Max and SE denote the mean value, minimum value, maximum value, and standard error, respectively. 


\subsection{Data Analysis: Model Specification, Parameterization and Evaluation}

Analytically, the relationship between $v_{d}$ and $t_{x}$ is hierarchical in nature in that it has been shown to vary systematically with $m_{x}$ (e.g., [12]). However, field-based assessments of the moisture effect within standing trees are difficult given the inability to experimentally manipulate or maintain constant moisture levels, due to naturally varying seasonal changes occurring throughout the growing season. Consequently, the effect of $m_{x}$ on the $v_{d}-t_{x}$ relationship was assessed indirectly via the employment of a two-level hierarchical, mixed-effects linear regression model (sensu [22]), where the parameters of the level one $v_{d}-t_{x}$ linear regression model specific to each individual sample tree were expressed as a function of the mean xylem moisture, as calculated from the $m_{x}$ measurements obtained over all 6 sampling events.

More specifically, graphical examination of the relationship between $v_{d}$ and $t_{x}$ for each sample tree revealed linear tendencies in which $v_{d}$ generally declined with increasing $t_{x}$ for both species. However, exceptions infrequently occurred for red pine, in which the inverse pattern was observed. Thus, a simple linear model was specified at the 1st hierarchical level (Equation (1)).

$$
v_{d(i j k)}=\pi_{0_{(j k)}}+\pi_{1_{(j k)}} t_{x(i j k)}+\varepsilon_{(i j k)}
$$

where $v_{d(i j k)}$ and $t_{x(i j k)}$ are the $i$ th temporal-based acoustic velocity-xylem temperature observational pair obtained from the $j$ th sample tree belonging to the $k$ th species $(i=1, \ldots, I, I=6 ; j=1, \ldots, J$, where $J=26$ for $k=1$ (red pine), and $j=1, \ldots, J$, where $J=36$ for $k=2$ (jack pine)), $\pi_{m_{(j k)}}, m=0,1$ are first-level intercept and slope parameters specific to the $j$ th sample tree and $k$ th species, and $\varepsilon_{(i j k)}$ is a random error term specific to the $i$ th $v_{d}-t_{x}$ observational pair, $j$ th sample tree, and $k$ th species.

At the 2nd hierarchical level, the first-stage parameters were expressed as a linear function of mean moisture (Equation (2)).

$$
\pi_{m(j k)}=\beta_{m 0(k)}+\beta_{m 1(k)} \bar{m}_{x(j k)}+U_{m_{(j k)}}
$$

where $m=0,1, \bar{m}_{x(j k)}$ is the mean xylem moisture specific to the $j$ th sample tree of $k$ th species $\left(\bar{m}_{x(j k)}=\sum_{i=1}^{I} m_{x(i j k)} / \sum_{i=1}^{I} i\right), \beta_{m n(k)}, n=0,1$ are species-specific second-level parameters reflecting the effect of mean xylem moisture on the $m$ th level-one parameter $(m=0,1)$, and $U_{m_{(j k)}}$ is the second-level random effect error specific to the $m$ th level-one parameter, $j$ th sample tree, and $k$ th species.

Thus, incorporating the second-level models back into the first-level model yields the two-level hierarchical, mixed-effects linear model specification (Equation (3)).

$$
v_{d(i j k)}=\beta_{00(k)}+\beta_{01(k)} \bar{m}_{x(j k)}+\beta_{10(k)} t_{x(i j k)}+\beta_{11(k)} \bar{m}_{x(j k)} t_{x(i j k)}+U_{0(j k)}+U_{1(j k)} t_{x(i j k)}+\varepsilon_{(i j k)}
$$

where $\beta_{i^{\prime} j^{\prime}(k)}, i^{\prime}=0,1$ and $j^{\prime}=0,1$ are species-specific model parameters. In accord with the statistical protocols advanced by Raudenbush and Bryk ([22]) and deploying the associated hierarchical linear and non-linear modeling software program HLM7 developed by Raudenbush et al. ([23]), model parameterization procedures consisted of generating empirical Bayes parameter estimates for the first-level coefficients, generalized least squares estimates for the second-level coefficients, and maximum-likelihood estimates for the variance and covariance components. As specified, the parameter estimates from the first-level and second-level regression relationships were initially treated as random.

Following parameterization, each species-specific model was assessed on its compliance with the following underlying statistical assumptions (sensu [22]): (1) Constant variance among level one residuals; and (2) inclusion of significant $(p \leq 0.05)$ random effects as determined via testing the null hypothesis, $U_{m_{(j k)}} \neq 0$, versus the alternative hypothesis, $U_{m_{(j k)}}=0$. The homogeneity of variance assumption was assessed using an inferential test statistic along with a data centric method: The H-statistic, as described by Raudenbush and Bryk ([22]), and Park's homogeneity test 
(sensu [22]), respectively. The two approaches were used given that when the number of observations within the first-level groups is less than 10, the H-test may be less rigorous than expected [22]. Analytically, Park's homogeneity test involved regressing the first stage Bayes residual values (logarithmic square values; dependent variable) against the predictive variable values (logarithmic values; independent variable) using a simple linear regression model specification followed by testing the null hypothesis that the resultant slope parameter estimate was not significantly different from zero, at the 0.05 probability level. Resultant slope values not significantly different from zero were supportive of the homoscedasticity assumption. Conversely, slope values significantly different from zero were suggestive of the presence of heteroscedasticity (non-constant variance).

Furthermore, given the effect of serial correlation on statistical inference in terms of potentially producing inefficient estimators without the minimum variance best linear unbiased estimator property when present, 1st-order serial correlation among the empirical Bayes residuals derived from the first-level models was assessed using the Box-Ljung Q-statistic (i.e., testing the null hypothesis that 1st order autocorrelation among consecutive residuals is not significantly different from zero at the 0.05 probability level). The presence of potential outliers or influential observations, systematic lack-of-fits, and non-constant variance was also assessed through the examination of predictor-residual error scatterplots generated for each species-specific model.

Subsequent to the evaluation of the applicability of these underlying assumptions, the species-specific parameterized models were evaluated on their goodness-of-fit, lack-of-fit, and predictive ability employing the following metrics: (1) Index of fit squared $\left(I^{2}\right.$; Equation (4)), which quantifies the proportion of variability in the dependent variable explained by the model and is analogous to the coefficient of determination, was employed as an overall goodness-of-fit measure; (2) lack-of-fit was determined through the analysis of the (i) multitude of the mean absolute biases $\left(\bar{B}_{a}\right.$; Equation (5)) and mean relative biases $\left(\bar{B}_{r}\right.$; Equation (6)) with respect to $95 \%$ confidence intervals, and (ii) linear regression relationship between the observed and predicted values (sensu [24]); and (3) absolute and relative prediction and tolerance error intervals were used to quantify predictive accuracy $[25,26]$.

$$
\begin{array}{r}
I_{(k)}^{2}=1-\frac{\sum_{j=1}^{J_{(k)}} \sum_{i=1}^{I_{(j k)}}\left(v_{d(i j k)}-\hat{v}_{d(i j k)}\right)^{2}}{\sum_{j=1}^{J_{(k)}} \sum_{i=1}^{I_{(j k)}}\left(v_{d(i j k)}-\bar{v}_{d(i j k)}\right)^{2}} \\
\bar{B}_{a(k)}=\frac{\sum_{j=1}^{J_{(k)}} \sum_{i=1}^{I_{(j k)}}\left(v_{d(i j k)}-\hat{v}_{d(i j k)}\right)}{J_{(k)} I_{(j k)}} i j \\
j=1 \\
\bar{B}_{r(k)}=\frac{\sum_{j=1}^{J_{(k)}} \sum_{i=1}^{I_{(j k)}} 100 \frac{\left(v_{d(i j k)}-\hat{v}_{d(i j k)}\right)}{v_{d(i j k)}}}{J_{j=1} \sum_{i=1}^{I_{(j k)}} i j}
\end{array}
$$

where $\hat{v}_{d(i j k)}$ is the model-based predicted acoustic velocity value.

\section{Results}

\subsection{Model Specifications, Parameter Estimates and Statistical Compliance with Assumptions}

Parameter estimates and associated regression statistics, including the results from the assessment of serial correlation for each species-specific model, are presented in Table 2. The resultant models included only significant $(p \leq 0.05)$ random effects, as determined from univariate and multivariate 
tests of significance (sensu [22]). All random effect terms were significant except for $U_{1}$ in the red pine model. These effects reflect the presence of random variation in the $v_{d}-t_{x}$ relationship among individual trees that could be partially explained by the second-stage predictor, mean xylem moisture level. The presence of serial correlation among the first-level Bayes residuals within individual tree sequences was assessed using autocorrelation coefficients in conjunction with the Box-Ljung Q statistic. The results indicated the presence of first-order serial correlation among consecutive residual values was minimal for red pine and non-existent for jack pine.

Graphical examination of residual scatterplots revealed concentrated circular-shaped data clusters which lack systematic trends, and hence were not inconsistent with the homogenous of variance and constant variance assumptions. Furthermore, results from inferential testing via the deployment of the H statistic (sensu [22]) and Park's data-centric regression approach [27] provided no consequential evidence to reject the homogenous of variance assumption (Table 2). In terms of goodness-of-fit measures, the jack pine model outperformed the red pine model in terms of the percentage of variation explained: $90 \%$ versus $64 \%$ (Table 3). Species-specific scatterplots of predicted versus observed values and associated regression relationships, along with resultant confidence intervals for absolute and relative biases, indicated that the models exhibited no consequential lack-of-fit (Table 3): (1) Species-specific intercept and scope parameter estimates of the predicted versus observed simple linear regressions were not significantly $(p \leq 0.05)$ different from zero and unity, respectively (Table 3); and (2) species-specific mean absolute and relative mean biases were not significantly $(p \leq 0.05)$ different from zero. The absolute and relative prediction intervals indicated that the expected error generated from using the parameterized functions would be unbiased and within $\pm 0.15 \mathrm{~km} / \mathrm{s}$ or $\pm 3.2 \%$ of the true value for red pine, and within $\pm 0.10 \mathrm{~km} / \mathrm{s}$ or $\pm 2.2 \%$ of the true value for jack pine (Table 3). The absolute and relative tolerance intervals indicated that $95 \%$ of the expected errors generated using the parameterized functions would fall within (1) $\pm 0.17 \mathrm{~km} / \mathrm{s}$ or $\pm 3.5 \%$ of the true values $95 \%$ of the time for red pine, and (2) $\pm 0.11 \mathrm{~km} / \mathrm{s}$ or $\pm 2.4 \%$ of the true values $95 \%$ of the time for jack pine (Table 3).

\subsection{Correction Models}

Analytically, the resultant parameterized model for red pine indicated that acoustic velocity measurements were significantly $(p \leq 0.05)$ affected by changes in xylem temperature and mean moisture levels. The corresponding model for jack pine indicated that acoustic velocity was significantly affected only by changes in xylem temperature. In the latter case, the potential effect of mean moisture level on the level one parameter estimates was reevaluated using the exploratory analysis option within the HLM7 software program (sensu [22]). Results from this supplemental assessment confirmed the final variable selection results and associated specification (i.e., the $v_{d}-t_{x}$ relationship for jack pine was not significantly affected by $\bar{m}_{x}$ at the 0.05 probability level).

Thus, based on the final specifications of the species-specific models (Table 2) and specifying 20 ${ }^{\circ} \mathrm{C}$ and $40 \%$ as reference xylem temperature and moisture conditions, the following correction models were parameterized deploying the HLM7 software program ([23]): Equation (7a) for red pine $(k=1)$ and Equation $(7 \mathrm{~b})$ for jack pine $(k=2)$.

$$
\begin{gathered}
\frac{v_{d(i j k)}}{\overline{\bar{v}}_{d\left(. . k ; t_{x}=20, m_{x}=40\right)}}=\beta_{00(k)}+\beta_{01(k)}\left(\bar{m}_{x(j k)}-40\right)+\beta_{10(k)}\left(t_{x(i j k)}-20\right)+\beta_{11(k)}\left(\bar{m}_{x(j k)}-40\right)\left(t_{x(i j k)}-20\right) \\
+U_{0(j k)}+\varepsilon_{(i j k)} \\
\frac{v_{d(i j k)}}{\bar{v}_{d\left(. . k ; t_{x}=20\right)}}=\beta_{00(k)}+\beta_{10(k)}\left(t_{x(i j k)}-20\right)+U_{0(j k)}+U_{1(j k)}\left(t_{x(i j k)}-20\right)+\varepsilon_{(i j k)}
\end{gathered}
$$

where $\bar{v}_{d\left(. . k ; t_{x}=20, m_{x}=40\right)}$ is the observed mean $v_{d}$ value calculated from 9 red pine tree measurements for which the conditions $19<t_{x}\left({ }^{\circ} \mathrm{C}\right) \leq 21$ and $39<m_{x}(\%) \leq 41$ were true, and $\bar{v}_{d\left(t_{x}=20\right)}$ is the observed mean $v_{d}$ value calculated from the 51 jack pine tree measurements for which the condition $19<t_{x}\left({ }^{\circ} \mathrm{C}\right)$ $\leq 21$ was true. 
Table 2. Species-specific parameter estimates and associated statistics for the hierarchical linear model (Equation (3)).

\begin{tabular}{|c|c|c|c|c|c|c|c|c|}
\hline \multirow{3}{*}{ Species } & \multicolumn{4}{|c|}{ Parameter Estimates } & \multicolumn{4}{|c|}{ Statistics and Validation of Assumptions } \\
\hline & \multirow[b]{2}{*}{$\beta_{00}$} & \multirow[b]{2}{*}{$\beta_{01}$} & \multirow[b]{2}{*}{$\beta_{10}$} & \multirow[b]{2}{*}{$\beta_{11}$} & \multirow[b]{2}{*}{$S E E^{\mathbf{a}}$} & \multicolumn{2}{|c|}{ Homogeneity of Variance ${ }^{b}$} & \multirow{2}{*}{$\begin{array}{c}\text { Independence } \\
n_{(\hat{p} \neq 0)}(\%)\end{array}$} \\
\hline & & & & & & $\mathbf{H}^{\mathbf{b}}$ & $\begin{array}{l}\text { Park's }^{\prime} \\
\text { Test }^{c}\end{array}$ & \\
\hline Red pine & 3.560464 & 0.034175 & 0.112081 & -0.002928 & 0.084 & $\mathrm{H}_{0}$ & $\mathrm{H}_{0}$ & $1(4)$ \\
\hline Jack pine & 4.494457 & ns & -0.004903 & ns & 0.057 & $\mathrm{H}_{0}$ & $\mathrm{H}_{0}$ & $0(0)$ \\
\hline
\end{tabular}

ns denote parameter estimates that were not significantly $(p<0.05)$ different from zero. ${ }^{a}$ SEE denotes the standard error of estimate in units of km/s. ${ }^{b}$ Homogeneity of variance test statistic $(\mathrm{H})$, where $\mathrm{H}_{0}$ indicates the non-rejection of the null hypothesis that the variance was homogenous at the 0.05 probability level (sensu [22]). ${ }^{c}$ Park's data-centric regression approach to assess the homogeneity of variance assumption, where $\mathrm{H}_{0}$ indicates the non-rejection of the null hypothesis that the variance was homogenous at the 0.05 probability level (sensu [27]). ${ }^{\mathrm{d}} n_{(\hat{p} \neq 0)}$ is the species-specific number of tree-specific relationships for which there was a significant $(p \leq 0.05)$ first-order autocorrelation coefficient estimate $(\hat{p})$ among consecutive first-stage residuals, as determined from the Box-Ljung $Q$ statistic.

Table 3. Goodness-of-fit and lack-of-fit statistics and predictive performance metrics.

\begin{tabular}{|c|c|c|c|c|c|c|c|c|c|c|c|}
\hline \multirow{4}{*}{ Species } & \multirow{4}{*}{$\begin{array}{c}\begin{array}{c}\text { Goodness-of-Fit } \\
\text { Statistic }\end{array} \\
\\
I^{2 \mathrm{a}}\end{array}$} & \multicolumn{6}{|c|}{ Lack-of-Fit Measures ${ }^{c}$} & \multicolumn{4}{|c|}{ Predictive Ability: 95\% Error Intervals $d$} \\
\hline & & \multicolumn{2}{|c|}{ Hypotheses $^{b}$} & \multicolumn{2}{|c|}{ Absolute } & \multicolumn{2}{|c|}{ Relative } & \multicolumn{2}{|c|}{ Prediction Interval } & \multicolumn{2}{|c|}{ Tolerance Interval } \\
\hline & & \multirow{2}{*}{$\alpha_{0}=0$} & \multirow{2}{*}{$\alpha_{1}=1$} & \multirow{2}{*}{$\begin{array}{c}\text { Mean Bias } \\
(\mathbf{k m} / \mathbf{s})\end{array}$} & \multirow{2}{*}{$95 \% \mathrm{CL}^{\mathrm{c}}$} & \multirow{2}{*}{$\begin{array}{c}\text { Mean Bias } \\
(\%)\end{array}$} & \multirow{2}{*}{$95 \% \mathrm{CL}^{\mathrm{c}}$} & Absolute & Relative & Absolute & Relative \\
\hline & & & & & & & & $\begin{array}{c}95 \% \text { CL } \\
(\mathrm{km} / \mathrm{s})\end{array}$ & $\begin{array}{c}95 \% \text { CL } \\
\text { (\%) }\end{array}$ & $\begin{array}{c}95 \% \text { CL } \\
(\mathrm{km} / \mathrm{s})\end{array}$ & $\begin{array}{c}95 \% \text { CL } \\
(\%)\end{array}$ \\
\hline Red pine & 0.638 & $\mathrm{H}_{0}$ & $\mathrm{H}_{0}$ & 0.000 & \pm 0.012 & 0.029 & \pm 0.253 & \pm 0.154 & \pm 3.175 & \pm 0.169 & \pm 3.477 \\
\hline Jack pine & 0.902 & $\mathrm{H}_{0}$ & $\mathrm{H}_{0}$ & 0.000 & \pm 0.007 & 0.017 & \pm 0.152 & \pm 0.100 & \pm 2.245 & \pm 0.108 & \pm 2.425 \\
\hline
\end{tabular}


Rearranging the resultant parameterized equations yielded the following correction equations: Equation (8a) for red pine and Equation (8b) for jack pine.

$$
\hat{v}_{d\left(t_{x}=20, m_{x}=40\right)}=\frac{v_{d\left(t_{x}, m_{x}\right)}}{\left(\begin{array}{c}
1.0-0.005040\left(m_{x}-40\right)-0.001044\left(t_{x}-20\right) \\
-0.000605\left(t_{x}-20\right)\left(m_{x}-40\right)
\end{array}\right)}
$$

where $v_{d\left(t_{x}, m_{x}\right)}$ is the observed acoustic velocity value for a red pine tree measured at an xylem temperature of $t_{x}$ and mean xylem moisture content of $m_{x}$, whereas $\hat{v}_{d\left(t_{x}=20, m_{x}=40\right)}$ is the corresponding acoustic velocity equivalent value, adjusted to the reference conditions, $t_{x}=20^{\circ} \mathrm{C}$ and $m_{x}=40 \%$.

$$
\hat{v}_{d\left(t_{x}=20\right)}=\frac{v_{d\left(t_{x}\right)}}{\left(1.0-0.001122\left(t_{x}-20\right)\right)}
$$

where $v_{d\left(t_{x}\right)}$ is the observed acoustic velocity value of a jack pine tree measured at an xylem temperature of $t_{x}$, whereas $\hat{v}_{d\left(t_{x}=20\right)}$ is the corresponding acoustic velocity equivalent value, adjusted to the reference condition, $t_{x}=20^{\circ} \mathrm{C}$.

Figures 1 and 2 exemplify the resultant correction equations developed for red pine and jack pine, respectively. Specifically, Figure 1 provides adjusted acoustic velocity estimates for a conceptually representative red pine tree, for which the velocity was set at a $4.84 \mathrm{~km} / \mathrm{s}$ value (mean value of the selected red pine sample trees used to obtain the $\bar{v}_{d\left(. . k ; t_{x}=20, m_{x}=40\right)}$ value) across 24 different moisture and temperature conditions (i.e., 4 moisture levels $(30 \%, 35 \%, 40 \%$, and $45 \%) \times 6$ temperatures $\left(5{ }^{\circ} \mathrm{C}\right.$, $10{ }^{\circ} \mathrm{C}, 15^{\circ} \mathrm{C}, 20^{\circ} \mathrm{C}, 25{ }^{\circ} \mathrm{C}$, and $\left.30^{\circ} \mathrm{C}\right)$ ). The percentage adjustments for the example cases shown, ranged from $-2.5 \%$ at the lowest temperature $\left(5{ }^{\circ} \mathrm{C}\right)$ to $+9.1 \%$ at the highest temperature $\left(30{ }^{\circ} \mathrm{C}\right)$ for the lowest moisture level considered (30\%). For the highest moisture level considered $(45 \%)$, the percentage adjustment ranged from $+3.5 \%$ at the lowest temperature $\left(5{ }^{\circ} \mathrm{C}\right)$ to $-7.1 \%$ at the highest temperature $\left(30^{\circ} \mathrm{C}\right)$. More importantly, however, within the context of the operable range of $v_{d}$ values observed for the red pine sample trees $(0.80 \mathrm{~km} / \mathrm{s}$; minimum of 4.49 to a maximum of $5.29 \mathrm{~km} / \mathrm{s})$, these percentage changes increase consequentially: (1) To $-15.3 \%$ at $5{ }^{\circ} \mathrm{C}$ and $+55.2 \%$ at $30{ }^{\circ} \mathrm{C}$, for a mean moisture level of $30 \%$; and (2) to $+20.9 \%$ at $5{ }^{\circ} \mathrm{C}$ and $-42.7 \%$ at $30^{\circ} \mathrm{C}$, for a mean moisture level of $45 \%$.

Similar to Figure 1, Figure 2 provides adjusted acoustic velocity estimates for a conceptually representative jack pine tree, for which the velocity was set at a $4.37 \mathrm{~km} / \mathrm{s}$ value (mean of the selected jack pine sample trees used to obtain the $\bar{v}_{d\left(. . k ; t_{x}=20\right)}$ value), across 6 temperatures $(5,10,15,20,25$, and $\left.30{ }^{\circ} \mathrm{C}\right)$ ). On a percentage basis, the magnitude of the adjustment ranged from $+1.7 \%$ at the lowest temperature $\left(5^{\circ} \mathrm{C}\right)$ to $-1.1 \%$ at the highest temperature $\left(30^{\circ} \mathrm{C}\right)$. However, within the context of the operable range of $v_{d}$ values observed for the jack pine sample trees $(0.85 \mathrm{~km} / \mathrm{s}$; minimum of 4.01 to a maximum of $4.86 \mathrm{~km} / \mathrm{s}$ ), these percentage changes also increase substantially: To $+8.5 \%$ at $5{ }^{\circ} \mathrm{C}$ and $-5.8 \%$ at $30^{\circ} \mathrm{C}$. 


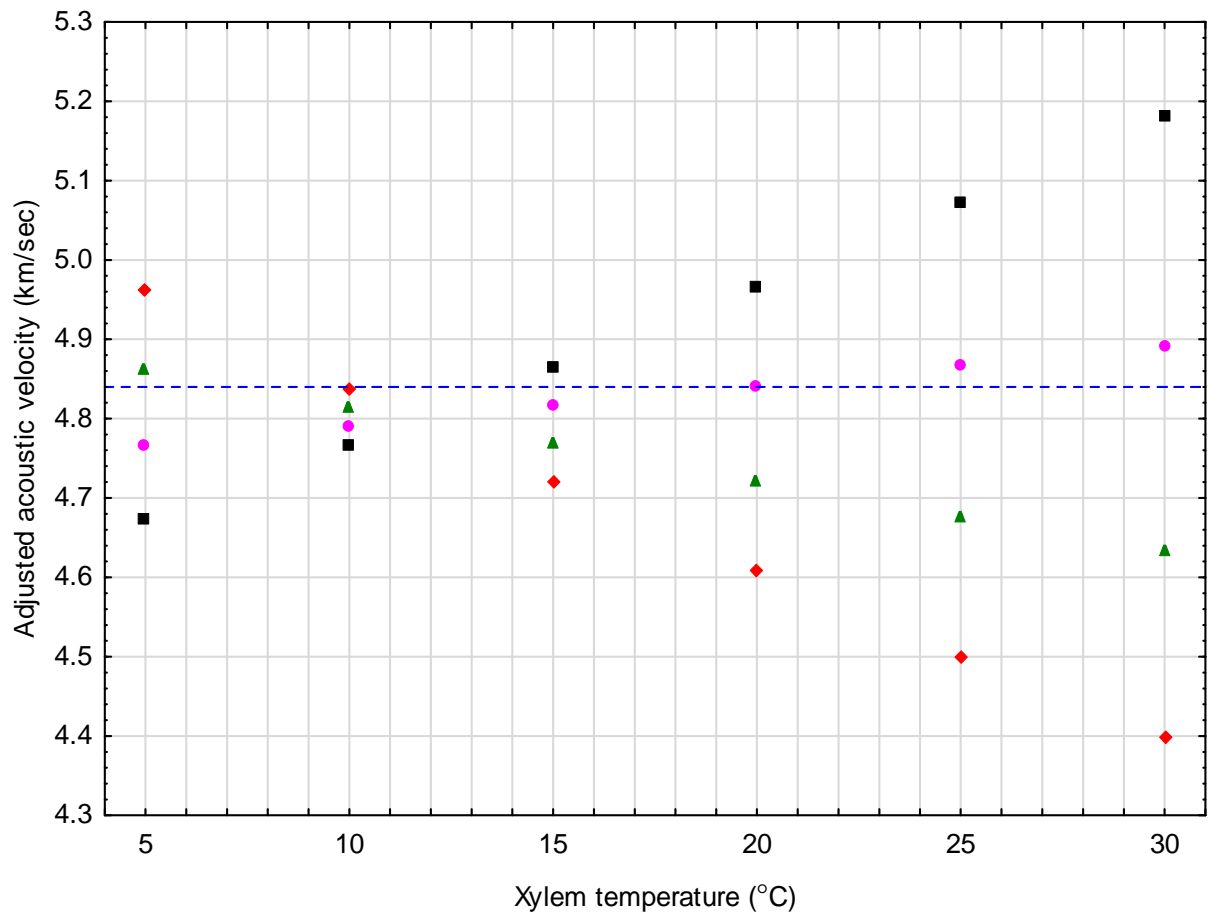

Figure 1. Graphical exemplification of the results from the red pine correction equation (Equation (8a)) when adjusting a constant observed acoustic value of $4.84 \mathrm{~km} / \mathrm{s}$ (denoted by horizontal dash-line) to standardized conditions $\left(t_{x}=20^{\circ} \mathrm{C}\right.$ and $\left.m_{x}=40 \%\right)$ for 4 mean moisture classes $(30 \%, 35 \%, 40 \%$, and $45 \%$ as denoted by solid diamond, triangle, circle, and square symbols, respectively) across a $5{ }^{\circ} \mathrm{C}-30$ ${ }^{\circ} \mathrm{C}$ temperature range.

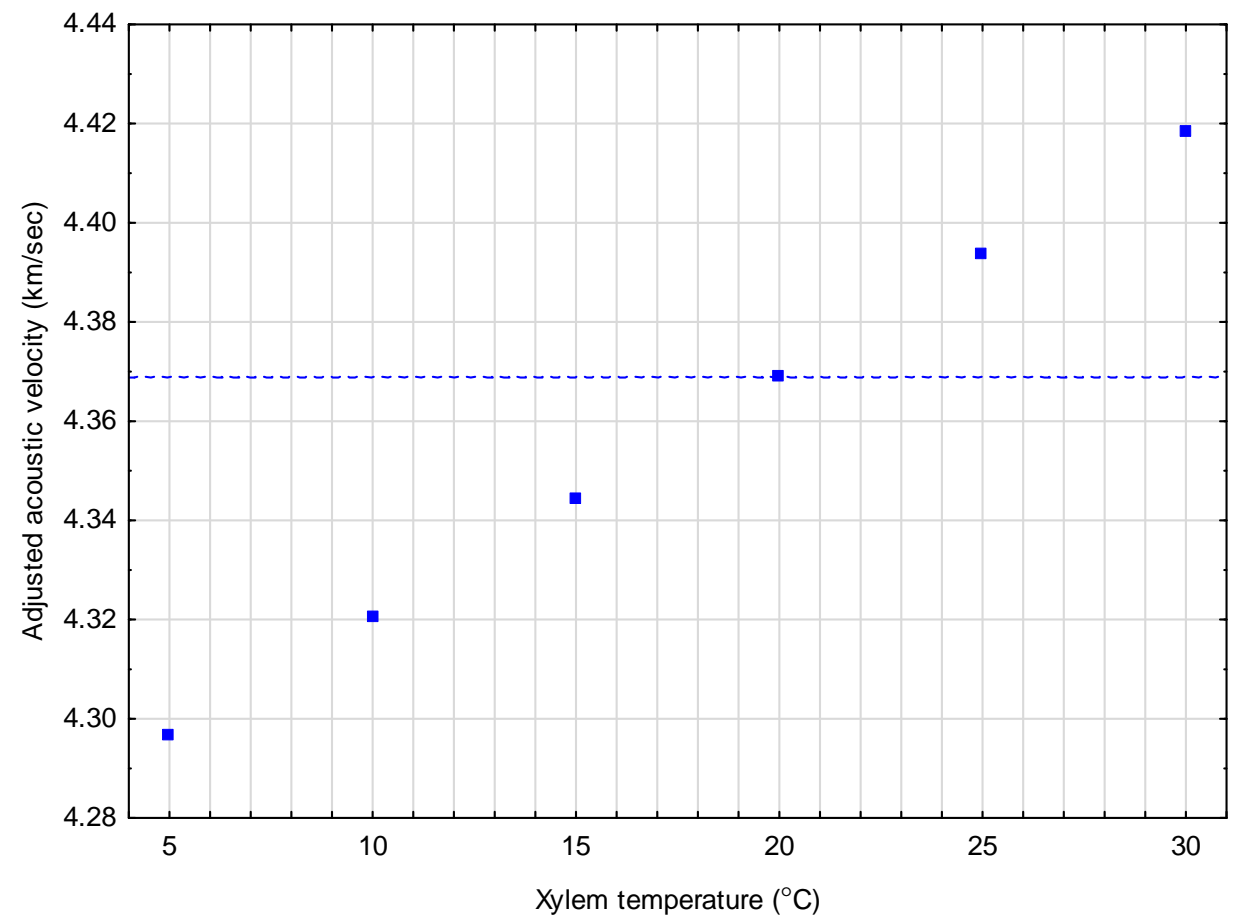

Figure 2. Graphical exemplification of the results from the jack pine correction equation (Equation (8b)) when adjusting a constant observed acoustic value of $4.37 \mathrm{~km} / \mathrm{s}$ (denoted by horizontal dash-line) to standardized conditions $\left(t_{x}=20^{\circ} \mathrm{C}\right)$ across a $5{ }^{\circ} \mathrm{C}-30{ }^{\circ} \mathrm{C}$ temperature range. 


\section{Discussion}

The primary objective of this study was to investigate the significance of xylem moisture effects on the relationship between acoustic velocity and xylem temperature within standing red pine and jack pine trees. Deploying an empirical-based sampling approach, consisting of replicated measurements of $v_{d}$ within the same set of plantation grown red pine and jack pine trees throughout the spring-to-autumn seasonal period, during which $t_{x}$ and $m_{x}$ varied naturally, combined with the subsequent statistical-based analytics involving the application of hierarchical, mixed-effects regression models, yielded statistically validated regression models. Specifically, the final model specifications were (1) comprised of only significant $(p \leq 0.05)$ dependent variables with the appropriate fixed and (or) and random effects included, (2) compliant with the underlying homogenous variance and independence statistical assumptions, (3) adequate in terms of the magnitude of $v_{d}$ variation explained (64\% for red pine and $90 \%$ for jack pine), (4) devoid of consequential evidence of systematic lack-of-fit issues, and (5) adequate in terms of predictive precision (e.g., absolute tolerance intervals indicated that $95 \%$ of the expected errors generated using the parameterized functions would fall within $\pm 0.17 \mathrm{~km} / \mathrm{s}$ (red pine) and $\pm 0.11 \mathrm{~km} / \mathrm{s}$ (jack pine) of their true value, $95 \%$ of the time).

Functionally, the $v_{d}-t_{x}$ relationship for red pine significantly $(p \leq 0.05)$ varied in a complex and systematic fashion with xylem moisture: $v_{d}$ increased with increasing $t_{x}$ at lower mean moisture levels $(<38 \%)$ but conversely decreased with increasing $t_{x}$ at higher mean moisture levels $(>38 \%)$. More generally, the $v_{d}-t_{x}$ relationship was directly proportional at the lower moisture levels, with the slope of relationship increasing in value with decreasing wood moisture, indicating that acoustic velocity was more sensitive to changes in temperature as moisture levels declined. For example, at lower moisture levels, acoustic velocity would increase by approximately $0.01 \mathrm{~km} / \mathrm{s}$ for every $1{ }^{\circ} \mathrm{C}$ increase in temperature when moisture was $35 \%\left(\beta_{10}+\beta_{11} \bar{m}_{x}\right.$, where $\bar{m}_{x}=35$ yields +0.0096 ; Table 2), versus $0.02 \mathrm{~km} / \mathrm{s}$ for every $1{ }^{\circ} \mathrm{C}$ increase in temperature when moisture was $30 \%\left(\beta_{10}+\beta_{11} \bar{m}_{x}\right.$, where $\bar{m}_{x}$ $=30$ yields +0.0242 ; Table 2 ). Conversely, the $v_{d}-t_{x}$ relationship was inversely proportional at the higher moisture levels, with the slope of relationship declining in value with increasing wood moisture, suggesting that acoustic velocity was more sensitive to changes in temperature as moisture levels increased. For example, at higher moisture levels, acoustic velocity would decrease by approximately $0.01 \mathrm{~km} / \mathrm{s}$ for every $1{ }^{\circ} \mathrm{C}$ increase in temperature when moisture was $40 \%$ (i.e., $\beta_{10}+\beta_{11} \bar{m}_{x}$, where $\bar{m}_{x}=40$ yields -0.0050 ; Table 2), versus a decrease of approximately $0.02 \mathrm{~km} / \mathrm{s}$ for every $1{ }^{\circ} \mathrm{C}$ increase in temperature when moisture was $45 \%\left(\beta_{10}+\beta_{11} \bar{m}_{x}\right.$, where $\bar{m}_{x}=45$ yields -0.0050 ; Table 2$)$. The threshold moisture value at which the $v_{d}-t_{x}$ relationships switched from directly proportional to inversely proportional was approximately $38.3 \%$ (i.e., $\beta_{10} / \beta_{11}$; Table 2 ). Conversely, the $v_{d}-t_{x}$ relationship for jack pine was not significantly $(p \leq 0.05)$ influenced by xylem moisture levels. The $v_{d}-t_{x}$ relationship was inversely proportional, with a constant slope across the temperature spectrum examined (i.e., -0.0049 ; Table 2). Empirically, this slope value indicates that acoustic velocity would decline by approximately $0.01 \mathrm{~km} / \mathrm{s}$ for every $1{ }^{\circ} \mathrm{C}$ increase in xylem temperature.

Given these analytical findings, that is, significant $(p \leq 0.05)$ relationships between $v_{d}$ and $t_{x}$ for both species, and the associated moderation effect of xylem moisture on the $v_{d}-t_{x}$ relationship within red pine stems, dictated the realization of the study's secondary objective: The development of correction models. Specifically, based on the final species-specific hierarchical model specifications, corresponding correction equations were developed for (1) adjusting observed acoustic velocity values measured at a specific xylem temperature of $t_{x}$ and moisture value of $m_{x}$ on a red pine tree $\left(v_{d\left(t_{x}, m_{x}\right)}\right)$ to corresponding acoustic velocity equivalents referenced to standardized temperature $\left(20{ }^{\circ} \mathrm{C}\right)$ and moisture $(40 \%)$ conditions $\left(v_{d\left(t_{x}=20, m_{x}=40\right)}\right)$ and (2) adjusting observed acoustic velocity values measured at a specific xylem temperature of $t_{x}$ on a jack pine tree $\left(v_{d\left(t_{x}\right)}\right)$ to corresponding acoustic velocity equivalents referenced to a standardized temperature $\left(20^{\circ} \mathrm{C}\right)\left(v_{d\left(t_{x}=20\right)}\right)$. Based on the range of xylem temperatures $\left(\approx 5{ }^{\circ} \mathrm{C}-30^{\circ} \mathrm{C}\right)$ and mean xylem moisture levels $(\approx 30-45 \%)$ observed within the sample tree population throughout the spring-to-autumn seasonal period, the magnitude of the average adjustment required would be in the order of $0.12 \mathrm{~km} / \mathrm{s}$ for red pine and $0.04 \mathrm{~km} / \mathrm{s}$ for jack pine. 
Although the decision to deploy the correction equations would be governed by the precision requirements of the acoustic sampler, it is noteworthy to consider the magnitude of these adjustments when expressed as percentage of the sample range of acoustic velocities observed across the sampling events. For example, for red pine, the operable range of $v_{d}$ values was approximately $0.80 \mathrm{~km} / \mathrm{s}$ (from a minimum of 4.49 to a maximum of $5.29 \mathrm{~km} / \mathrm{s}$ ), and hence the mean relative adjustment required would be in the order of $15 \%$. More precisely, however, when calculating adjustment values for specific temperature and moisture conditions, the percentage adjustments increase consequentially: For example, (1) $-15.3 \%$ at $5{ }^{\circ} \mathrm{C}$ and $+55.2 \%$ at $30{ }^{\circ} \mathrm{C}$ for a moisture level of $30 \%$; and (2) to $+20.9 \%$ at $5{ }^{\circ} \mathrm{C}$ and $-42.7 \%$ at $30{ }^{\circ} \mathrm{C}$ for a moisture level of $45 \%$. Similarly, for jack pine, the operable range of $v_{d}$ values was approximately $0.85 \mathrm{~km} / \mathrm{s}$ (from a minimum of 4.01 to a maximum of $4.86 \mathrm{~km} / \mathrm{s}$ ), and hence the mean relative adjustment required would be in the order of $5 \%$. Likewise, however, the relative adjustment within the context of the operable range of $v_{d}$ values would not be as dramatic as that for red pine but would still increase by $+8.5 \%$ at $5{ }^{\circ} \mathrm{C}$ and $-5.8 \%$ at $30{ }^{\circ} \mathrm{C}$. Again, while the decision to implement the correction equations when acoustic sampling is ultimately related to the precision requirements of the end-user, these percentage-based results nevertheless illustrate the potential operational importance of their deployment when sampling; particularly during conditions in which xylem temperature and moisture levels approach the extremities of their spring-to-autumn seasonal ranges.

Acoustic-based methods belong to a broader suite of evolving technologies that can assist the forest management and research communities in the non-destructive estimation of internal wood quality characteristics (see [28] for a comprehensive summary). Briefly, in addition to acoustic-based approaches for estimating the dynamic modulus of elasticity, wood density, microfibrial angle, cell wall thickness, fiber coarseness, and specific surface area within standing trees via time-of-flight tools (e.g., Director ST300 (Fibre-gen Inc.); [7]) or within harvested logs via resonance instruments (Hitman ST200 (Fibre-gen Inc.); [29]), these innovative technologies include (1) mechanical-based physical resistance measures for wood density estimation via amplitude metrics derived from micro-drill resistance profiles (e.g., Resistograph micro-drill tool (IML, Inc., Moultonborough, NH, USA); [7,30]) or penetration measures arising from impact tools (e.g., Pilodyn impact device [31]), and (2) electromagnetic-based, near-infrared spectroscopic methods for estimating wood density, microfibrial angle, modulus of elasticity, and cell wall thickness (e.g., [32]).

In reference to the acoustic approaches, it is noteworthy to appreciate that the relationship between acoustic velocity and the dynamic modulus of elasticity for standing trees is different from that specified for harvested logs. The latter relationship employs the velocity of a mechanically induced longitudinal stress wave, rather than the velocity of a mechanically induced dilatational or quasi-dilatational stress wave which is measured within standing tree stems [33]. Although the wave types differ, along with their functional relationships with the dynamic modulus of elasticity, the two wave velocities have shown to be empirically correlated with each other for a number of coniferous species including Sitka spruce (Picea sitchensis (Bong.) Carr.), western hemlock (Tsuga heterophylla (Raf.) Sarg), jack pine, ponderosa pine (Pinus ponderosa Dougl. ex Laws.), radiata pine (Pinus radiata D. Don), and red pine $([7,8,34])$. This degree of concordance between the velocity measures within standing trees, and those within derived logs across multiple species, provides a measure of confirmatory support for acoustic-based estimation of internal wood fiber attributes.

The application of the acoustic approach, in terms of forecasting wood stiffness and other commercially-relevant attributes, could result in more precise prediction of end-product potential during pre-harvest assessments and surveys. These predictions could be used to inform segregation decision-making, and thus potentially contribute to increased allocation efficiencies along the upstream portion of the forest products supply chain. Similarly, fiber attribute predictions derived from validated acoustic-based relationships could be more widely employed as indirect surrogate measures of wood quality within silvicultural research studies. Overall, the acoustic approach represents an efficient economic alterative to the logistically challenging and expensive destructive methods used to 
determine commercially relevant fiber attributes (e.g., Silviscan [35]). Although these presuppositions highlight the positive potentials of the acoustic approach, its ultimate deployment will be largely dependent on the precision requirements and associated error tolerances of the end-user.

The empirical results reported to date have been largely supportive of the acoustic approach in terms of the statistical significance of the fiber prediction relationships. However, the degree of variation among the studies in terms of exploratory power (percentage of variation explained) and predictive ability (precision) suggest improvements may be required if attaining precise point-estimates of stiffness are required. For example, with respect to results reported for red pine [7] and jack pine [8], the $m_{e}-v_{d}$ relationships were both statistically significant at the 0.05 probability level, explained $42 \%$ (red pine) and $71 \%$ (jack pine) of the variation in $m_{e}$, and were able to provide point estimates at an expected precision level of approximately $\pm 1.5 \mathrm{GPa}$ (red pine) and $\pm 2.7 \mathrm{GPa}$ (jack pine). Operationally, however, even when assuming that the standing tree $m_{e}$ estimate would be approximately equal to its static counterpart within a derived solid wood end-product (e.g., dimensional lumber), the acoustic-based estimates would not be precise enough to sort standing trees into NLGA (National Lumber Grades Authority)-based grade classes, given that their classes differ by an average of only $\pm 0.7 \mathrm{GPa}$ (Table 2 in the NLGA grading guidelines ([36])). Collectively, these results and associated inferences suggest that identifying and accounting for consequential sources of variation could be advantageous to advancing the acoustic approach in both forest operations and silvicultural research.

Accordingly, this study concentrated on investigating the significance of two of the most important known sources of acoustic velocity variation, as previously identified in the literature: Xylem temperature and xylem moisture (e.g., [9-12,37]). These previous studies have revealed a range of consequential effects particularly in terms of those arising from temperature variation. Similar to this study, analytical solutions, via the provision of correction or adjustment equations, have also been derived from these analyses. Overall, the consequences of the effects are most concerning when xylem moistures fall below fiber saturation thresholds, or when xylem temperatures fall below the freezing point $\left(0^{\circ} \mathrm{C}\right)$. Published results most pertinent to this study are those provided by Gao et al. [10], who investigated temperature effects on standing red pine trees. Their findings, based on acoustic velocity and temperature sampling of 20 red pine trees throughout a full year, combined with the deployment of a segmented linear regression model, revealed that acoustic velocity decreased linearly by approximately $0.007 \mathrm{~km} / \mathrm{s}$ for every $1{ }^{\circ} \mathrm{C}$ increase in ambient air temperature across a $0{ }^{\circ} \mathrm{C}$ to $30^{\circ} \mathrm{C}$ range. This rate of change is in accordance with that reported here for red pine (e.g., decline of $0.005 \mathrm{~km} / \mathrm{s}$ per $1{ }^{\circ} \mathrm{C}$ increase at $40 \%$ xylem moisture; Table 2) and jack pine (decline of $0.005 \mathrm{~km} / \mathrm{s}$ per $1{ }^{\circ} \mathrm{C}$ increase; Table 2).

Although assessing other more correlative-based sources of variation, such as tree-to-tree acoustic velocity variation arising from growth-induced differences in wood structure, would be of utility (e.g., [38]), focusing on the underlying known causal sources, such as xylem temperature and moisture, was a logical first step. Furthermore, the provision of species-specific correction equations, which accounted for such variation, should contribute to minimizing the effects of environmental variability on the precision of acoustic-derived estimates of commercially relevant fiber attributes when deploying the acoustic approach.

\section{Conclusions}

The relationship between the dynamic modulus of elasticity of xylem tissue and acoustic velocity has been established for a number of commercially important coniferous species. However, results from previous investigations suggest the relationship may be effected by xylem temperature and moisture variation. Consequently, this study investigated the significance of these effects on acoustic velocity measurements within standing red pine and jack pine trees through (1) temporal and repeated sampling of the same set of red pine and jack pine sample trees throughout the spring-to-autumn seasonal period, and (2), given (1), statistical inference of the derived species-specific, statistically validated, hierarchical, linear, mixed-effects regression models. The results indicated that acoustic velocity was influenced by temperature for both species, whereas the influence of moisture was only observed for red pine. 
Resultantly, species-specific correction equations for adjusting observed acoustic velocity measurements to corresponding equivalents referenced to standardized temperature and moisture conditions were developed. Although the spatial concentration of the sample sites with respect to the species geographic ranges, along with the limited sample sizes, suggest that caution should be exercised when drawing conclusive statistical inferences or deploying the derived relationships outside of the study region, this study has demonstrated the consequential effects of environmental variability on acoustic velocity measures. Furthermore, the provision of quantitative solutions for accounting for these effects should be of utility when deploying the acoustic approach in forest operations and silvicultural research.

Funding: Canadian Wood Fibre Centre, Canadian Forest Service, Natural Resources Canada

Acknowledgments: The author expresses his appreciation to (1) Gordon Brand and Mark Primavera of the Great Lakes Forestry Centre (GLFC), Canadian Forest Service (CFS), Natural Resources Canada (NRCan) for their assistance during the 2016 and 2017 field data acquisition campaigns, respectively; (2) Canadian Wood Fibre Centre, CFS, NRCan for fiscal support relating to equipment procurement, field sampling expenses and journal reporting; and (3) anonymous referees for insightful and constructive review comments and suggestions.

Conflicts of Interest: The author declares no conflict of interest.

\section{References}

1. Rowe, J.S. Forest Regions of Canada; Publication No. 1300; Government of Canada, Department of Environment, Canadian Forestry Service: Ottawa, ON, Canada, 1972.

2. Zhang, S.Y.; Koubaa, A. Softwoods of Eastern Canada: Their Silvics, Characteristics, Manufacturing and End-Uses; Special Publication SP-526E; FPInnovations: Quebec City, QC, Canada, 2008.

3. Ross, R.J. Nondestructive Evaluation of Wood, 2nd ed.; General Technical Report FPL-GTR-238; USDA, Forest Service, Forest Products Laboratory: Madison, WI, USA, 2015; p. 169.

4. National Lumber Grades Authority (NLGA). Standard Grading Rules for Canadian Lumber; NLGA: Surrey, BC, Canada, 2014; p. 316.

5. Hong, Z.; Fries, A.; Lunqvist, S.-O.; Gull, B.A.; Wu, H.X. Measuring stiffness using acoustic tool for Scots pine breeding selection. Scand. J. For. Res. 2015, 30, 363-372. [CrossRef]

6. Mora, C.R.; Schimleck, L.R.; Isik, F.; Mahon, J.M.; Clark, A.; Daniels, R.F. Relationships between acoustic variables and different measures of stiffness in standing Pinus taeda trees. Can. J. For. Res. 2009, 39, 1421-1429. [CrossRef]

7. Newton, P.F. Acoustic-based non-destructive estimation of wood quality attributes within standing red pine trees. Forests 2017, 8, 380. [CrossRef]

8. Newton, P.F. In-forest acoustic-based prediction of commercially-relevant wood quality attributes within standing jack pine trees. For. Chron. 2018. submitted.

9. Gao, S.; Wang, X.; Wang, L.; Allisson, R.B. Effect of temperature on acoustic evaluation of standing trees and logs: Part 1-Laboratory investigations. Wood Fiber Sci. 2012, 44, 286-297.

10. Gao, S.; Wang, X.; Wang, L.; Allisson, R.B. Effect of temperature on acoustic evaluation of standing trees and logs: Part 2: Field investigation. Wood Fiber Sci. 2013, 45, 15-25.

11. Moreno-Chan, J.; Walker, J.C.; Raymond, C.A. Effects of moisture content and temperature on acoustic velocity and dynamic MOE of radiata pine sapwood boards. Wood Sci. Technol. 2010, 4, 609-626. [CrossRef]

12. Llana, F.L.; Iñiguez-Gonzalez, G.; Martitegui, A.; Niemz, P. Influence of temperature and moisture content on non-destructive measurements in Scots pine wood. Wood Res. 2014, 59, 769-780.

13. Llana, D.F.; Íñiguez-González, G.; Martínez, R.D. Influence of timber moisture content on wave time-of-flight and longitudinal natural frequency in coniferous species for different instruments. Holzforschung 2018, 72, 405-411. [CrossRef]

14. Unterwieser, H.; Schickhofer, G. Influence of temperature and moisture content on the dynamic properties of ungraded spruce boards. Eur. J. Wood Prod. 2012, 70, 629-638. [CrossRef]

15. Carter, P.; Briggs, D.; Ross, R.J.; Wang, X. Acoustic testing to enhance western forest values and meet customer wood quality needs. In Productivity of Western Forests: A Forest Products Focus; Harrington, C.A., Schoenholtz, S.H., Eds.; Gen. Tech. Rep. PNW-GTR-642; USDA, Forest Service, Pacific Northwest Research Station: Portland, OR, USA, 2005; pp. 121-129. 
16. Wang, X.; Carter, P.; Ross, R.J.; Brashaw, B.K. Acoustic assessment of wood quality of raw materials: A path to increased profitability. For. Prod. J. 2007, 57, 6-14.

17. Filipescu, C.N.; Trofymow, J.A.; Koppenaal, R.S. Late-rotation nitrogen fertilization of douglas-fir: Growth response and fibre properties. Can. J. For. Res. 2017, 47, 134-138. [CrossRef]

18. Lenz, P.; Auty, D.; Achim, A.; Beaulieu, J.; Mackay, J. Genetic improvement of white spruce mechanical wood traits-Early screening by means of acoustic velocity. Forests 2013, 4, 575-594. [CrossRef]

19. Beckwith, A.F.; Roebbelen, P.; Smith, V.G. Red Pine Plantation Growth and Yield Tables; Forest Research Report No. 108; Ontario Ministry of Natural Resources; Ontario Tree Improvement and Forest Biomass Institute: Maple, ON, Canada, 1983.

20. Carmean, W.H.; Niznowski, G.P.; Hazenberg, G. Polymorphic site index curves for jack pine in Northern Ontario. For. Chron. 2001, 77, 141-150. [CrossRef]

21. Wilson, F.G. Numerical expression of stocking in term of height. J. For. 1946, 44, 758-761.

22. Raudenbush, S.W.; Bryk, A.S. Hierarchical Linear Models: Applications and Data Analysis Methods, 2nd ed.; Sage: Newbury Park, CA, USA, 2002; p. 485.

23. Raudenbush, S.W.; Bryk, A.S.; Cheong, Y.F.; Congdon, R.T.; Toit, M., Jr. HLM 7-Hierarchical Linear and Nonlinear Modeling; Scientific Software International Inc.: Lincolnwood, IL, USA, 2011; p. 360.

24. Ek, A.R.; Monserud, R.A. Performance and comparison of stand growth models based on individual tree and diameter-class growth. Can. J. For. Res. 1979, 9, 231-244. [CrossRef]

25. Reynolds, M.R., Jr. Estimating the error in model predictions. For. Sci. 1984, 30, 454-469.

26. Gribko, L.S.; Wiant, H.V., Jr. A SAS template program for the accuracy test. Compiler 1992, 10, 48-51.

27. Gujarati, D.N. Essential of Econometrics, 3rd ed.; McGraw-Hill/Irwin Inc.: New York, NY, USA, 2006 ; p. 553.

28. Rudnicki, M.; Wang, X.; Ross, R.J.; Allison, R.B.; Perzynski, K. Measuring Wood Quality in Standing Trees: A Review; General Technical Report FPL-GTR-248; USDA, Forest Service, Forest Products Laboratory: Madison, WI, USA, 2017; p. 11.

29. Newton, P.F. Predictive relationships between acoustic velocity and wood quality attributes for red pine logs. For. Sci. 2017, 63, 504-517. [CrossRef]

30. Rinn, F.; Schweingruber, R.H.; Schär, E. Resistograph and X-ray density charts of wood: Comparative evaluation of drill resistance profiles and X-ray density charts of different wood species. Holzforschung 1996, 50, 303-311. [CrossRef]

31. Wu, S.J.; Xu, J.M.; Li, G.Y.; Risto, V.; Lu, Z.H.; Li, B.Q.; Wang, W. Use of the pilodyn for assessing wood properties in standing trees of Eucalyptus clones. J. For. Res. 2010, 21, 68-72. [CrossRef]

32. Tsuchikawa, S.; Kobori, H. A review of recent application of near infrared spectroscopy to wood science and technology. J. Wood Sci. 2015, 61, 213-220. [CrossRef]

33. Wang, X.; Carter, P. Acoustic assessment of wood quality in trees and logs. In Nondestructive Evaluation of Wood, 2nd ed.; General Technical Report FPL-GTR-238; Ross, R.J., Ed.; USDA, Forest Service, Forest Products Laboratory: Madison, WI, USA, 2015; pp. 87-102.

34. Wang, X.; Ross, R.J.; Carter, P. Acoustic evaluation of wood quality in standing trees. Part I. Acoustic wave behavior. Wood Fiber Sci. 2007, 39, 28-38.

35. Defo, M.; Goodison, A.; Nelson, U. A method to map within-tree distribution of fibre properties using SilviScan-3 data. For. Chron. 2009, 85, 409-414. [CrossRef]

36. National Lumber Grades Authority (NLGA). Special Products Standard for Machine Graded Lumber; NLGA: Surrey, BC, Canada, 2013; p. 40.

37. Kang, H.; Booker, R.E. Variation of stress wave velocity with MC and temperature. Wood Sci. Technol. 2002, 36, 41-54. [CrossRef]

38. Bérubé-Deschênes, A.; Franceschini, T.; Schneider, R. Factors affecting plantation grown white spruce (Picea glauca) acoustic velocity. J. For. 2016, 114, 629-637. [CrossRef]

(C) 2018 by the author. Licensee MDPI, Basel, Switzerland. This article is an open access article distributed under the terms and conditions of the Creative Commons Attribution (CC BY) license (http:/ / creativecommons.org/licenses/by/4.0/). 